\title{
PERAN MEDIA SOSIAL DI ERA TRANSFORMASI DIGITAL SEBAGAI SARANA KOMUNIKASI KARANG TARUNA MASYARAKAT KAMPUNG PARUNG SERAB CILEDUG
}

\author{
Yunus $^{1 *}$ \\ Slamet Raharjo ${ }^{2}$ \\ Murni Handayani ${ }^{3}$ \\ Natasya Arifah ${ }^{4}$ \\ Rafli 5 \\ Nuraini Sitepu ${ }^{6}$ \\ Allam Ramzy ${ }^{7}$ \\ Widuri Indana Saleha ${ }^{8}$
}

1,2,3,4,5,6,7,8Universitas Pamulang, BANTEN, Indonesia

$\underline{\text { nurhang542@gmail.com }}^{{ }^{*} \text { ) }}$

Kata Kunci: [Media

Sosial, Komunikasi,

Karang Taruna,

Masyarakat]

Published by:

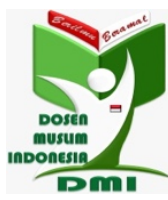

Abstrak: Peran media sosial di era transformasi pada kampung serab ciledug masih belum maksimal dalam penggunaan media sosial maka dari itu pengabdian kepada masyarakat (PKM) yang dilakukan pada organisasi karang taruna kampung parung serab ini bertujuan untuk memberikan edukasi ataupun arahan dalam memanfaatkan media sosial di era transformasi digital saat ini. Sehingga ketika organisasi karang taruna kampung parung serab ciledug dalam melaksanakan kegiatan di wilayah organisasi tersebut, dapat menyalurkan kembali informasi yang didapat dari kegiatan pengabdian kepada masyaraat (PKM) ini. Maka dengan diadakannya kegiatan pengabdian kepada masyarakat ini dapat membantu karang taruna kampung parung serab ciledug untuk dapat meningkatkan produktivitas dan efisiensi dalam menggunakan media sosial. Sehingga dengan begitu dapat membantu memaksimalkan kegiatan karang taruna kampung parung serab ciledug.

Copyright (c) 2021 The Author(s)

This article is licensed under CC BY 4.0 License (cc) $\mathrm{BY}$

https://dmi-journals.org/jai/ 


\section{Pendahuluan}

Peran media sosial di era transformasi pada kampung serab ciledug masih belum maksimal dalam penggunaan media sosial (Yunus, 2019). Maka dengan diadakannya kegiatan pengabdian kepada masyarakat ini diharapkan dapat membantu karang taruna kampong parung serab ciledug untuk dapat meningkatkan produktivitas dan efisiensi dalam menggunakan media sosial (Herdiansah, Sumadinata, Padjajaran, \& Padjajaran, 2019; Sari, 2020). Sehingga dengan begitu dapat membantu memaksimalkan kegiatan karang taruna kampung parung serab ciledug. Berdasarkan hasil pengamatan di lapangan terdapat permasalahan yang dialami oleh organisasi karang taruna kampung parung serab ciledug. Berbagai masalah yang terjadi karena dengan hadirnya media sosial dapat menimbulkan perilaku menyimpang dan mudah terhasut dalam menerima informasi (Annisa, 2020; Kharisma, 2017).

Pengabdian kepada masyarakat yang dilakukan pada organisasi karang taruna kampung parung serab bertujuan untuk memberikan edukasi ataupun arahan dalam memanfaatkan media sosial di era transformasi digital saat ini (Pratiwi, 2013). Sehingga ketika organisasi karang taruna kampung parung serab ciledug dalam melaksanakan kegiatan di wilayah organisasi tersebut, dapat menyalurkan kembali informasi yang didapat dari kegiatan pengabdian kepada masyaraat (PKM) ini.

\section{Metode Pelaksanaan}

Tahapan dan metode yang dilakukan pada kegiatan in adalah panitia melakukan survey dan wawancara kepada beberapa warga Kampung Parung Serab Ciledug sudah sejauh mana mereka memahami dan mengerti tentang penggunaan media sosial di era tranformasi ini yang sudah ada di kampung mereka, sehingga berdasarkan data tersebut,panitia mengusulkan kegiatan tatap muka ini dengan menambah pengetahuan para warga dalam menghadapai tantangan pembelajaran offline yang mau tidak mau harus dilakukan di masa pandemi. Adapun sebelum kegiatan ini dilaksanakan,panitia sudah melakukan wawancara dan pendekatan melalui ketua karang taruna di KAMPUNG PARUNG SERAB CILEDUG, dan dari hasil wawancara tersebut didapatkan usulan atau masukan dari ketua karang taruna agar panitia melakukan kegiatan berbentuk seminar dan presentasi sebagai pembekalan kepada para warga dalam menggunakan media sosial yang sudah ada di kampung mereka.

\section{Hasil dan Pembahasan}

Adapun detail dari informasi kegiatan seminar ini adalah sebagai berikut :

\section{Waktu dan Tempat Pelaksanaan}

Hari dan Tangga Pelaksanaan : Jumat, 09 April 2021

Waktu Pelaksanaan

: Pk. 19.00 Wib - Pk. 20.45 Wib

Tempat Pelaksanaan : Kampung Parung Serab dan Virtual Conference (Aplikasi Zoom)

\section{Tahapan Pelaksanaan (Susunan Acara)}

Adapun susunan acara pelaksanaan adalah sebagai berikut (Lihat Tabel 1): 
Tabel 1: Susunan Acara

\begin{tabular}{cclc}
\hline No. & Waktu & \multicolumn{1}{c}{ Acara } & Penanggung Jawab \\
\hline 1. & $19.00-19.15$ & Pembukaan Oleh MC & Nuraini Sitepu \\
2. & $19.15-19.30$ & Sambutan Dospem & Slamet Raharjo S.Si, M.Kom, \\
& & & MVP, VCP, COBIT5 \\
3. & $19.30-19.40$ & Penyampaian Materi 1 & Natasya Arifa \\
4. & $19.40-19.50$ & Penyampaian Materi 2 & Allam Ramzy P.H \\
5. & $19.50-20.00$ & Penyampaian Materi 3 & Widuri Indana Saleha \\
6. & $20.00-20.10$ & Penyampaian Materi 4 & Kafli \\
7. & $20.10-20.20$ & Tanya Jawab & Kelompok dan Audience \\
8. & $20.20-20.30$ & Penutup & Kelompok \\
9. & $20.30-20.40$ & Penyerahan Souvenir & - \\
10. & $20.40-20.45$ & Dokumentasi & \\
& & & \\
& & &
\end{tabular}

\section{Kegiatan}

Adapun dokumentasi dari kegiatan seminar offline tentang peran media sosial di era transformasi digital sebagai sarana komunikasi karang taruna masyarakat KAMPUNG PARUNG SERAB CILEDUG adalah sebagai berikut:

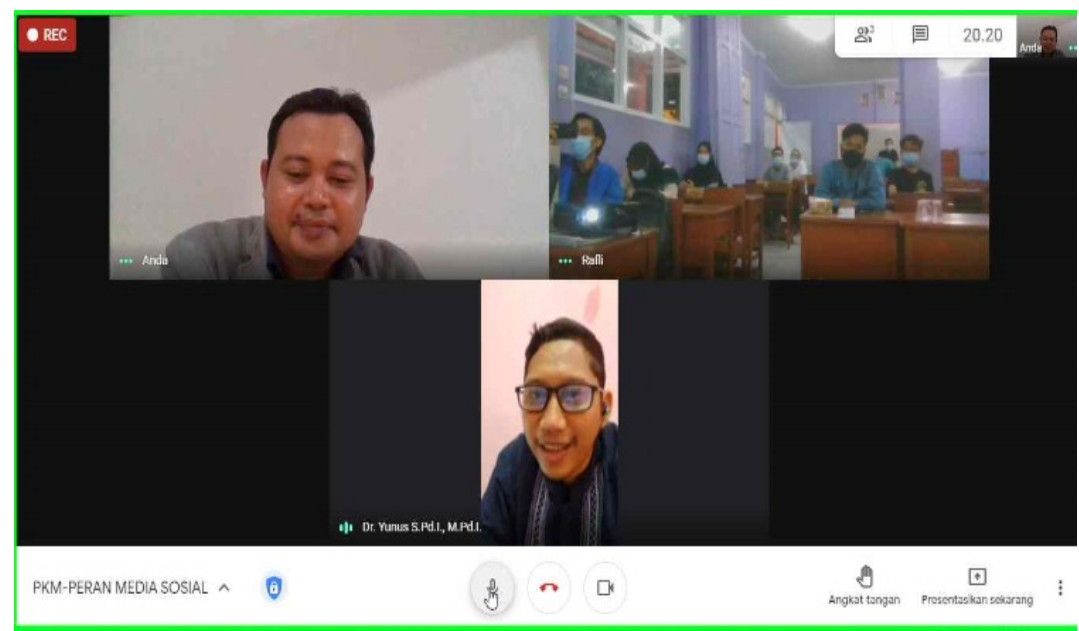

Gambar 1. Kata Sambutan dari Dosen Pembimbing dengan menggunakan google meet 


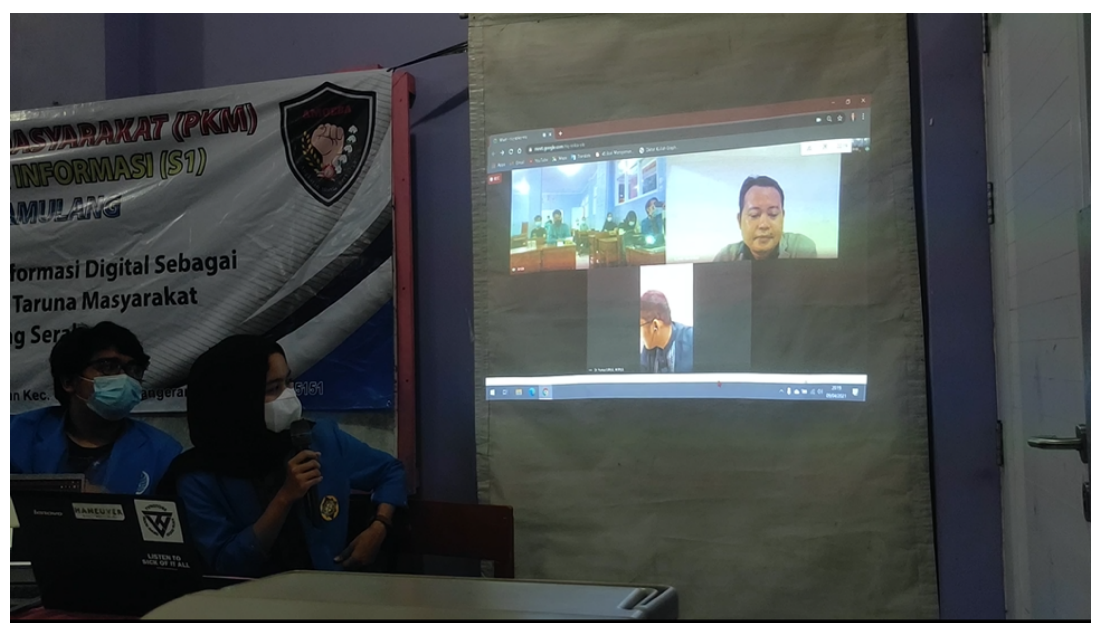

Gambar 2. Pembukaan acara oleh Nuraini Sitepu

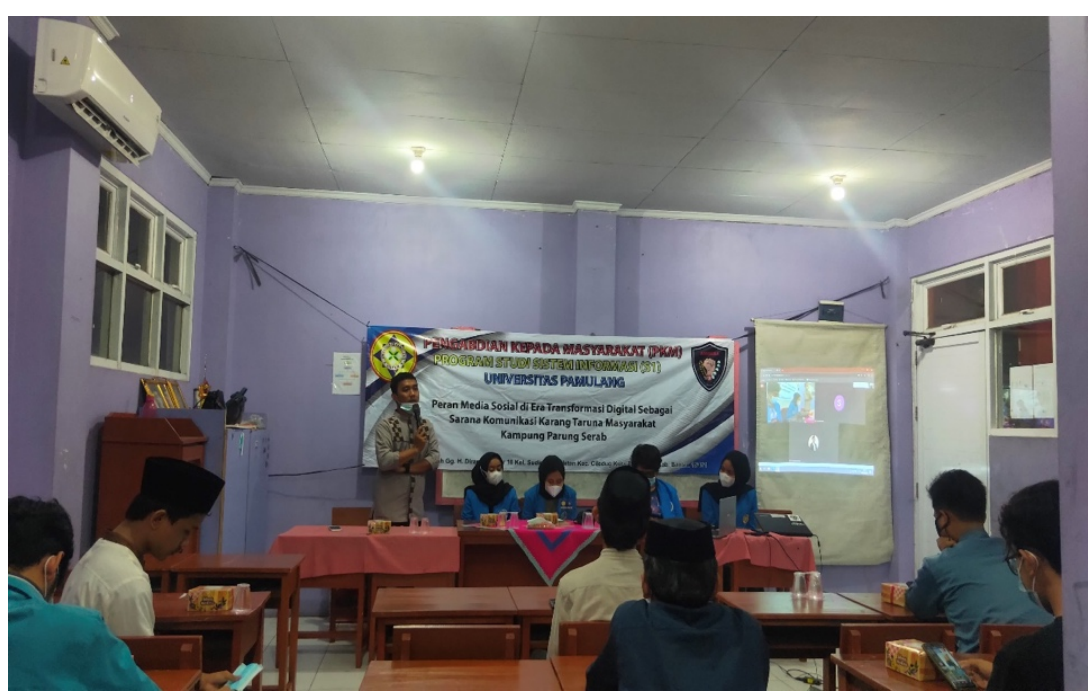

Gambar 3. Sambutan dari ketua Amoeba

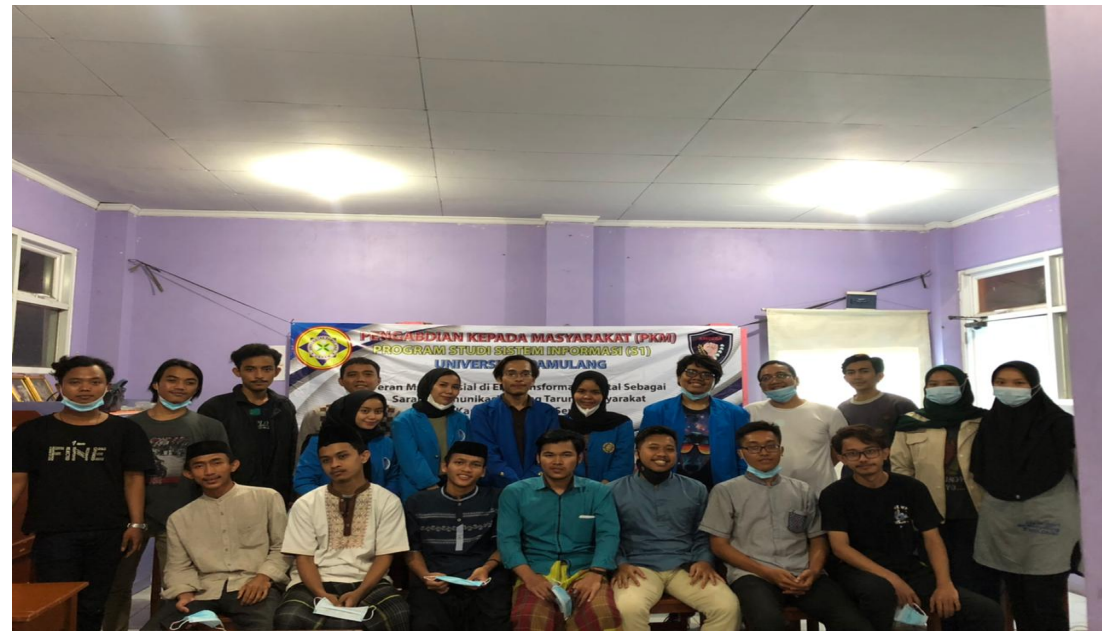

Gambar 4. Dokumentasi setelah selesai kegiatan 
Vol. 1. No. 2, Agustus 2021

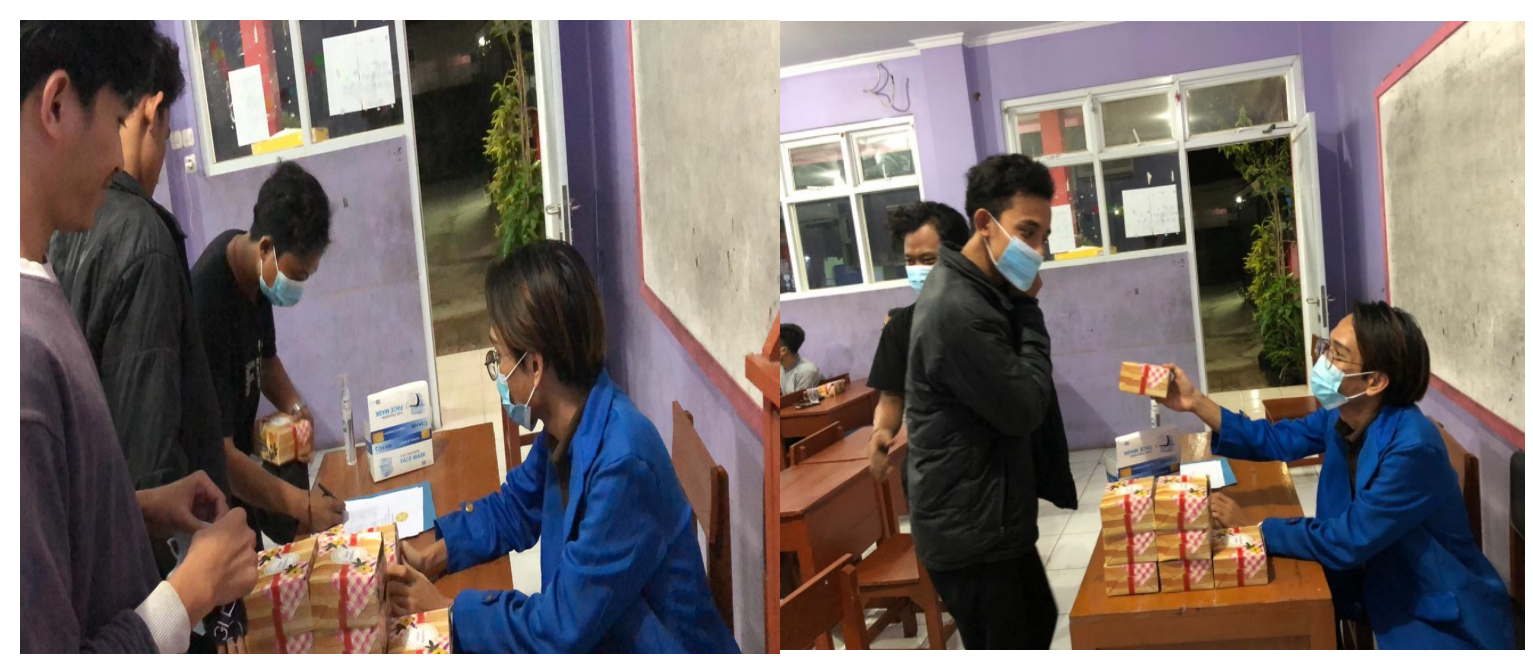

Gambar 5. Dokumentasi absensi dan pemberian snack

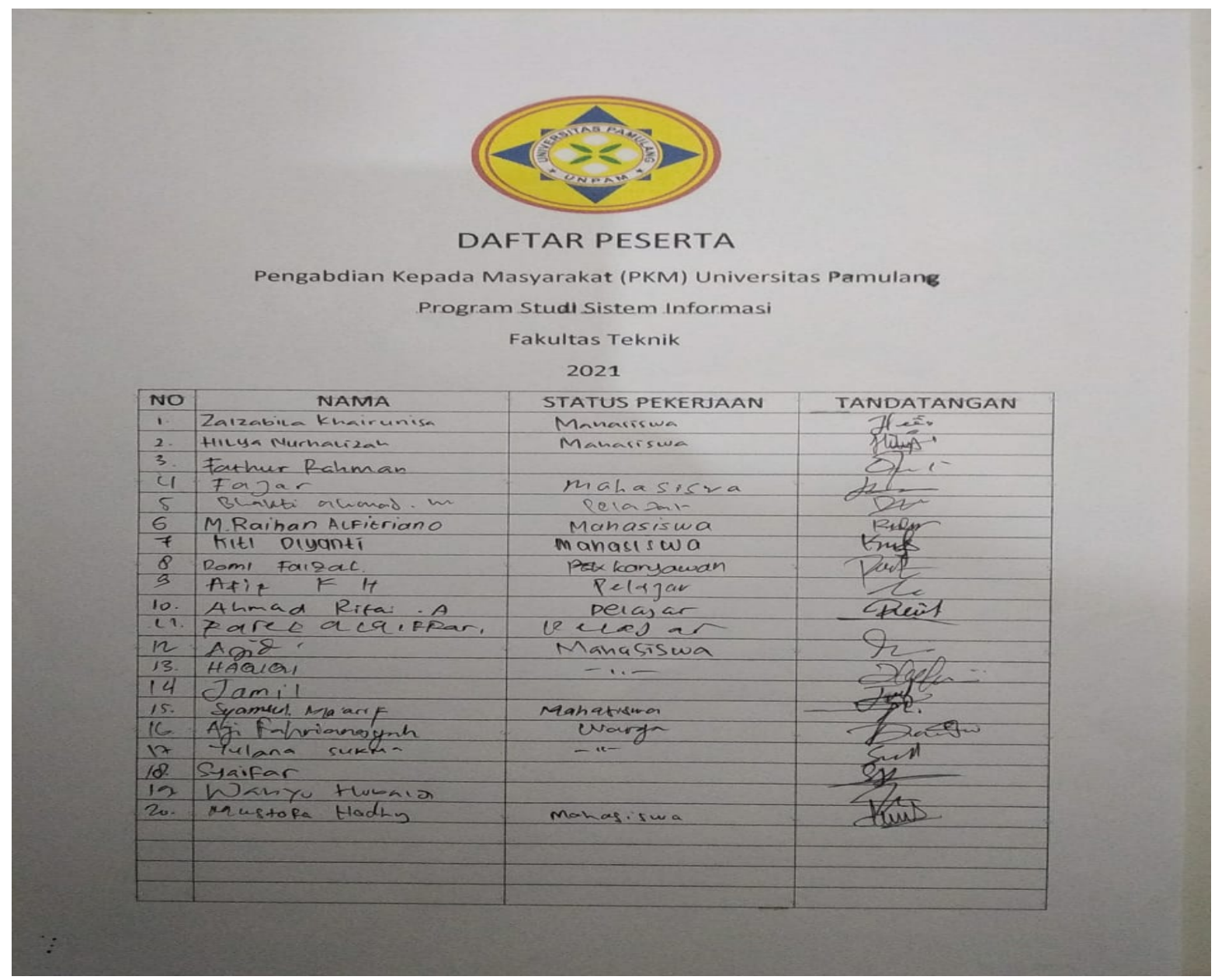

Gambar 6. Dokumentasi daftar hadir

Media sosial adalah alat komunikasi yang digunakan oleh pengguna dalam proses sosial.Sedangkan Transformasi digital adalah penggunaan teknologi untuk mentransformasi proses analog menjadi digital. Kita telah mengalami digitalisasi di semua bidang dalam hidup kita mulai dari jam tangan cerdas sampai asisten rumah tangga berkemampuan kecerdasan buatan.Peran media sosial di era transformasi pada kampung serab ciledug masih belum maksimal dalam penggunaan media sosial maka dari 
itu Pengabdian kepada masyarakat yang dilakukan pada organisasi karang taruna kampung parung serab ini bertujuan untuk memberikan edukasi ataupun arahan dalam memanfaatkan media sosial di era transformasi digital saat ini. Sehingga ketika organisasi karang taruna kampung parung serab ciledug dalam melaksanakan kegiatan di wilayah organisasi tersebut, dapat menyalurkan kembali informasi yang didapat dari kegiatan pengabdian kepada masyaraat (PKM) ini. Maka dengan diadakannya kegiatan pengabdian kepada masyarakat ini dapat membantu karang taruna kampung parung serab ciledug untuk dapat meningkatkan produktivitas dan efisiensi dalam menggunakan media sosial. Sehingga dengan begitu dapat membantu memaksimalkan kegiatan karang taruna kampung parung serab ciledug.

\section{Kesimpulan}

Dari kegiatan Pengabdian Kepada Masyarakat ini dapat diambil kesimpulan bahwa Harus selalu menambah wawasan dan meningkatkan keterampilan tentang pembelajaran dan pendidikan anak usia dini dan kepada masyarakat. Harus lebih mempersiapkan media pembelajaran yang akan digunakan harus lebih aktif berkomunikasi dengan anak-anak dan juga orang-orang tua.

\section{Ucapan Terimakasih}

Penulis dengan segala kerendahan hati menyampaikan ucapan terima kasihkepada Bapak Dede Supriyadi S.Kom, M.Kom selaku Ka. Prodi Program Sarjana Universitas Pamulang. Bapak Nurhalim, S.Ag selaku Ketua RW Kampung Parung Serab Ciledug. Bapak Wahyu Hubaidi selaku Ketua Karang Taruna Kampung Parung Serab Ciledug.

\section{Referensi}

Annisa, N. (2020). Keefektifan Dakwah Melalui Media Sosial di Masa Pandemi. https://doi.org/10.31219/osf.io/a7cz5

Herdiansah, A. G., Sumadinata, W. S., Padjajaran, U., \& Padjajaran, U. (2019). Indonesia' s political culture in the new digital age : A preliminary discussion Budaya politik Indonesia di era digital baru : Suatu diskusi pendahuluan. Masyarakat, Kebudayaan Dan Politik, 32(4), 378-389.

Kharisma, T. (2017). Konflik SARA pada Pilkada DKI Jakarta di Grup WhatsApp dengan Anggota Multikultural. Jurnal Penelitian Komunikasi, 20(2), 107-120. https://doi.org/10.20422/jpk.v20i2.233

Pratiwi, F. D. (2013). Benih Anarkisme Mahasiswa dan Media Sosial (Analisis Isi Pesan Twitter Mahasiswa Fishum Uin YOGYAKARTA). Profetik, 6(2), 5-16.

Sari, Y. I. (2020). Sisi Terang Pandemi Covid-19. Jurnal Ilmiah Hubungan Internasional, O(0), 89-94. https://doi.org/10.26593/jihi.v0i0.3878.89-94

Yunus, yunus. (2019). PENGARUH TI MEDIA SOSIAL TERHADAP PRESTASI BELAJAR PENDIDIKAN AGAMA ISLAM PESERTA DIDIK DI SMP NEGERI 3. Jurnal Teknologi Informasi ESIT, M(1), 16-25.Meryana, E. 2009. Kelemahan Produk UMKM di Indonesia: Kemasan. Artikel online. $\mathrm{h} \mathrm{t} \mathrm{t} p: / / \mathrm{b}$ i s n i s k e u a $\mathrm{n}$ g a $\mathrm{n}$. kompas.com/read/2012/07/29/15022184/about.h tml (d i a k s e stanggal 12 Oktober 2020) 
Vol. 1. No. 2, Agustus 2021

Wang, R W.Y. dan Chen, W C. 2007. The Study on Packaging Illustration Affect On Buying Emotion. Proceeding. International Association of Societies and Design Research, Hong Kong Polytech University (15 November 2007). 